\title{
Okun's Law over the Business Cycle: Was the Great Recession All That Different?
}

\author{
Michael T. Owyang and Tatevik Sekhposyan
}

\begin{abstract}
In 1962, Arthur Okun posited an empirical relationship between the change in the unemployment rate and real output growth. Since then, the media, policymakers, pundits, and intermediate macro students have used the so-called Okun's law as a rule of thumb to relate changes in unemployment to changes in output growth. However, some studies have suggested that the relationship has not been stable over time. Furthermore, the slow recovery of U.S. unemployment relative to output after the Great Recession has led some to question whether Okun's law has changed permanently. In this light, the authors reconsider the evidence on instability in Okun's law and, in particular, examine whether the Great Recession has contributed to the breakdown of the empirical relationship. (JEL C22, E32)
\end{abstract}

Federal Reserve Bank of St. Louis Review, September/October 2012, 94(5), pp. 399-418.

Many macroeconomic textbooks contain a rule of thumb relating real output growth to changes in the unemployment rate. $\underline{1}$ This relationship, called Okun's law after Okun (1962), typically assigns a 2- to 3-percentage-point decrease in real gross domestic product (GDP) growth to a 1-percentage-point increase in the unemployment rate. 2 Unlike laws in the physical sciences (e.g., Newton's laws of motion), Okun's law is an (arguably loose) empirical correlation and is, in general, neither theoretically motivated nor strictly adhered to in the data. $\frac{3}{}$ As many of the reduced-form relationships build strictly on associations and not causation, Okun's law appears to vary depending on the sample period studied.

The recent economic experience in the United States following the Great Recession (2007:Q4-2009:Q2) has prompted considerable doubts about the nature of Okun's law. In particular, during the recovery from the Great Recession, the United States has experienced a sustained high level of unemployment during a period of positive output growth, which is symptomatic of so-called jobless recoveries. Thus, there have been concerns in policy circles that the apparent correlation between different measures of unemployment and output fluctuations has weakened over time. We take a closer look at the past three recessions when the jobless recovery phenomenon was documented as more prevalent (see Engemann and Owyang, 2010). In addition, we

Michael T. Owyang is a research officer and economist at the Federal Reserve Bank of St. Louis. Tatevik Sekhposyan is a senior analyst at the Bank of Canada. The authors thank E. Katarina Vermann for research assistance.

( ) 2012, The Federal Reserve Bank of St. Louis. The views expressed in this article are those of the author(s) and do not necessarily reflect the views of the Federal Reserve System, the Board of Governors, the regional Federal Reserve Banks, or the Bank of Canada. Articles may be reprinted, reproduced, published, distributed, displayed, and transmitted in their entirety if copyright notice, author name(s), and full citation are included. Abstracts, synopses, and other derivative works may be made only with prior written permission of the Federal Reserve Bank of St. Louis. 


\section{Owyang and Sekhposyan}

investigate whether the correlation between unemployment and output fluctuations has been significantly different during the Great Recession and the follow-up recovery. Furthermore, some interesting differences in the behavior of Okun's law are apparent if unemployment rates for specific demographic groups are studied; we allude to some of these differences.

The balance of the paper is organized as follows: The next section reviews the history of Okun's law, including alternative representations and some criticisms. In the following section, we posit three alternative representations of Okun's law that allow for shifts in the relationship across the business cycle. We then consider the empirical evidence, which is followed by our conclusion.

\section{OKUN'S LAW}

Okun's (1962) seminal paper regarding the unemployment-output relationship considers the measurement of potential output. Okun believed that the potential output should not be defined as the maximum output the economy could (unconditionally) produce. Instead, he argued that the potential should be measured at full employment, which he characterized as the level of employment absent inflationary pressures, or the level of the non-accelerating rate of unemployment (NAIRU). ${ }^{4}$ Consequently, at the business cycle frequency the deviations of unemployment from a level such as the NAIRU could be correlated with the deviations of output from its trend.

Using quarterly data from 1947:Q2 to 1960:Q4, Okun regressed changes in the unemployment rate on changes in the log of real gross national product (GNP):

$$
\Delta u_{t}=\alpha^{d}+\beta^{d} \Delta y_{t}+e_{t}^{d}
$$

where $u_{t}$ is the unemployment rate, $y_{t}$ is the natural log of output measured with real GNP, and, because we consider alternative specifications later in the paper, the superscript $d$ indicates that these coefficients are specific to the "difference" specification. Based on his sample period, Okun found that $\hat{\alpha}^{d}=0.3$ and $\hat{\beta}^{d}=-0.3$, leading to the conclusion that a 1-percentage-point decrease in the real GNP growth rate was associated with a 0.3 -percentage-point increase in the unemployment rate. The textbook relationship is derived by inverting Okun's result: If a 1-percentagepoint decrease in real GNP growth is associated with a 0.3-percentage-point increase in the unemployment rate, then a 1-percentage-point increase in the unemployment rate must be associated with an approximate 3-percentage-point decrease in real output growth.

In addition to equation (1), Okun estimated a version relating the level of the unemployment rate to the output gap, $y_{t}^{g}$, for a quarterly sample from 1953:Q1 to 1960:Q4:

$$
\begin{aligned}
& u_{t}=\alpha^{g}+\beta^{g}\left(y_{t}-y_{t}^{n}\right)+e_{t}^{g} \\
& =\alpha^{g}+\beta^{g} y_{t}^{g}+e_{t}^{g},
\end{aligned}
$$

where $y_{t}^{n}$ is the time-varying path of potential output and $y_{t}^{g}=y_{t}-y_{t}^{n}$ is the output gap. Okun cites a 3.5 percent constant trend line as an example of a path for potential output. Based on the sample period considered, his reported estimates were $\hat{\alpha}^{g}=3.72$ and $\hat{\beta}^{d}=-0.36$, which suggests 
that a 3-percentage-point negative deviation of output from its trend is associated with a 1-percentage-point increase in the unemployment rate. In this case, the constant represents the natural rate of unemployment-the rate at which the output gap is zero.

Over the years, the simple empirical relationship has come under fire for its lack of a theoretical foundation. Moreover, Plosser and Schwert (1979) show that the standard interpretation of the textbook version of Okun's law has faulty econometric foundations. They show that inverting the regression relationship in equation (1) cannot be accomplished by inverting the coefficients-that is, the estimates $\hat{\alpha}$ and $\hat{\beta}$ obtained from

$$
\Delta y_{t}=\alpha+\beta \Delta u_{t}+e_{t}
$$

are not necessarily equal to $\hat{\alpha}=-\hat{\alpha}^{d} / \hat{\beta}^{d}$ and $\hat{\beta}=1 / \hat{\beta}^{d}$, where $\hat{\alpha}^{d}$ and $\hat{\beta}^{d}$ are the estimates from equation (1). The true slope coefficients in equations (1) and (3) are functions of covariances between $\Delta y_{t}$ and $\Delta u_{t}$, as well as the variances of the independent variables in the respective regressions. Consequently, with simple algebra, the authors show that the inversion of the slope coefficients is valid only when the variables $\Delta y_{t}$ and $\Delta u_{t}$ are perfectly correlated-that is, if the relationship between the two variables is deterministic. Using a different subsample (1953:Q11970:Q4) than Okun, Plosser and Schwert (1979) show that - when estimated directly-a 1-percentage-point increase in the unemployment rate is, on average, associated with a 1.6percentage-point decrease in real output growth, about half the size of the standard (and incorrect) interpretation suggested by the textbook rule.

A vast amount of empirical research since Okun (1962) and Plosser and Schwert (1979) has focused on estimating the textbook specification of Okun's law as opposed to inverting the relationship originally stated by Okun. Depending on the dataset, the period used for the estimation, and the estimation method, the estimate changes. For example, using the same dataset, Attfield and Silverstone (1997) find that the coefficient for the United States changes from 0.67 to 2.25 when accounting for a cointegrating relationship. Sönger and Stiassny (2002) provide some evidence that the size of the coefficient can also vary by country.

Studies have also addressed the possibility of structural breaks in the relationship between the unemployment rate and output growth. Knotek (2007) associates changes in Okun's coefficient with business cycles in the United States: The coefficient is, on average, smaller (in absolute value) in expansions than during recessions. Knotek also finds that the contemporaneous correlation has decreased over time, while the dynamic correlation - that is, the correlation with the lagged values of output growth measures-has increased. This asymmetric behavior of the Okun's coefficient over the business cycle is further reinforced by the findings of Beaton (2010) for both U.S. and Canada. Recent empirical phenomena, such as the Great Moderation (the period roughly between 1984 and 2007 described by low volatility on multiple time series in the data) and the financial crisis that followed, may have altered the relationship between output and unemployment fluctuations. For example, Daly and Hobijn (2010) note that the Great Recession was marked by a persistent deviation from Okun's empirical relationship. They argue that, in 2009, unemployment rose well in excess of what would be predicted by Okun's law. Daly and Hobijn (2010) attribute this deviation to an unusual rise in labor productivity.

However, analyzing small samples of data on the unemployment rate and output growth often calls unwarranted attention to apparent statistical anomalies. The question at hand is 


\section{Owyang and Sekhposyan}

whether such deviations can be construed as statistically significant shifts in Okun's law and, if so, whether the observed time variations are large relative to the ones observed previously throughout economic history. We address this question in the remainder of the paper.

An important aspect of this analysis is the nature of the data used. Some studies such as Knotek's (2007) use real-time data, whereas Daly and Hobijn (2010) consider the revised data available at the time of the analysis. Depending on the data used, the conclusions might differ. For instance, when comparing 2002:Q1-2010:Q4 output growth and unemployment rate data from the January 2011 and 2012 vintages, we find that the between-vintage root mean squared deviation for output growth is 10 times larger than that of the unemployment rate, which could make a difference for Okun's coefficient. - Since we are concerned with the "true" nature of the relationship between output growth and unemployment fluctuation as opposed to the predictive performance of Okun's law, we abstract from the real-time aspects of the data.

\section{EMPIRICAL MODELS}

In order to consider time variation in the relationship between unemployment and output fluctuations, as well as to consider measures of uncertainty around our point estimates, we conduct a regression-based analysis. We consider three benchmark specifications for Okun's law consistent with Knotek's (2007) approach, where equations (1) and (2) are referred to as "difference" and "gap" specifications, respectively, and are consistent with the original formulations of Okun's law. In addition, we consider an extension of the original Okun's law that allows the current and past values of output growth to affect the changes in the unemployment rate differently:

$$
\Delta u_{t}=\alpha^{l}+\beta^{l} \Delta y_{t}+\beta_{1}^{l} \Delta y_{t-1}+\beta_{2}^{l} \Delta y_{t-2}+\gamma_{1}^{l} \Delta u_{t-1}+\gamma_{2}^{l} \Delta u_{t-2}+e_{t}^{l}
$$

Equation (4) is the distributed lag version of the familiar difference specification in equation (1); we refer to this formulation of Okun's law as a "dynamic" specification. In this case, the change in the unemployment rate is determined jointly with lags of itself and lagged and current changes in output growth.

Our analysis relies on revised data observed at a quarterly frequency. The variables are seasonally adjusted and standardized in percentage points. The sample period includes 1949:Q12011:Q4 and the data vintage is February 17, 2012. Output growth is measured as the quarterover-quarter (non-annualized) growth rate of real GDP. Data from the Federal Reserve Economic Data (FRED) database of the Federal Reserve Bank of St. Louis are used for real GDP (series ID GDPC96) and the civilian unemployment rate (UNRATE). $\underline{6}$ Since unemployment is a monthly series and real GDP is a quarterly series, an aggregation method is necessary. We use the quarterly average of the monthly series as a quarterly observation for the unemployment rate. We consider two measures of output gap. The first one is obtained from the band-passed (BP) level of real GDP to obtain fluctuations between 6 quarters and 8 years. ${ }^{7}$ The second measure is from the Congressional Budget Office (CBO), the methodology of which is detailed in a $2004 \mathrm{CBO}$ background paper.

Figure 1 compares the two measures of output gap. It is obvious that there are drastic differences between the two-at least after 1979. The correlation for the overlapping periods is 0.79 . 


\section{Figure 1}

\section{Various Measures of Output Gap}

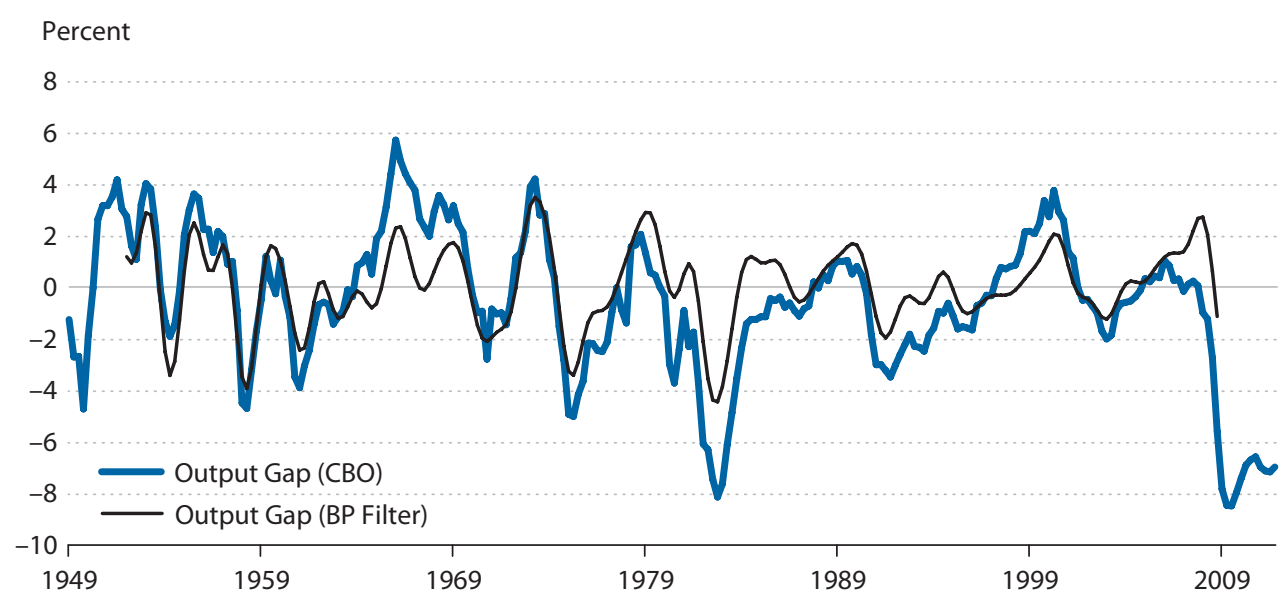

Therefore, it is not surprising that, depending on the measure of output gap used, the inference could be different. Figure 2 summarizes the data and shows the unconditional contemporaneous correlations between the unemployment rate and output growth/gap. The solid black circles show the observations pertaining to the Great Recession and the follow-up recovery. It is important to note that no particular dates stand out as explicit outliers. Interestingly, the correlation is the highest when the CBO's specification of output gap is used. Though the observations since the Great Recession are consistent with the average proportionality observed in the data, they are mainly concentrated in the area of a high output gap and a high unemployment rate, at least based on the CBO's estimate of the output gap.

Part of our interest is determining whether Okun's law changes during recessions. In particular, we are interested in whether Okun's law has changed significantly and in a historically unprecedented manner during the past three U.S. recessions, all of which had jobless recoveries. In addition, we investigate whether Okun's law has changed more during the Great Recession than in a typical recession, thus questioning whether the Great Recession was an uncommon period.

We use two approaches to answer the questions posed. First, we incorporate an indicator (dummy) variable $d_{t}$ for recession periods in various specifications of Okun's law. More particularly, we allow for both slope and level changes by introducing the recession dummies in the mean and interaction terms with the output variable; these account for the average variability of Okun's law during recessions relative to "normal" times. In order to assess the time variation in this relationship over specific recessions-as opposed to all recessions on average-we also consider a fixed rolling window estimation. In this particular case, we consider all possible 12-year subsamples starting at the beginning of our full sample and moving sequentially by one time period. We choose 12 years to roughly capture at least one recession in each rolling window estimation. For the reported results, the reported date corresponds to the end of the 12-year subsample. 


\section{Owyang and Sekhposyan}

\section{Figure 2}

\section{Okun's Law in Difference and Gap Specifications}

\section{A. Difference Specification}

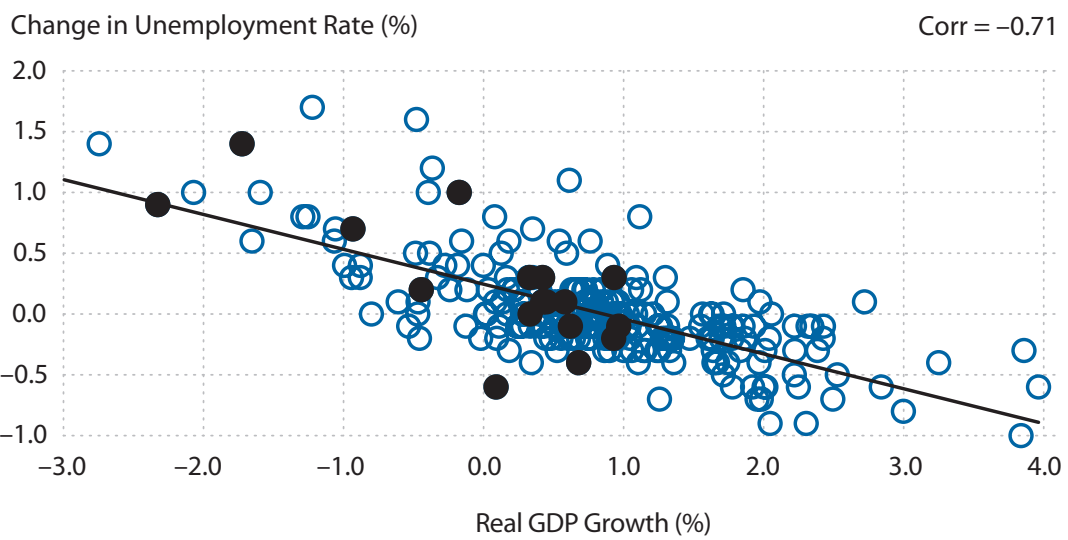

\section{B. Gap Specification (CBO)}

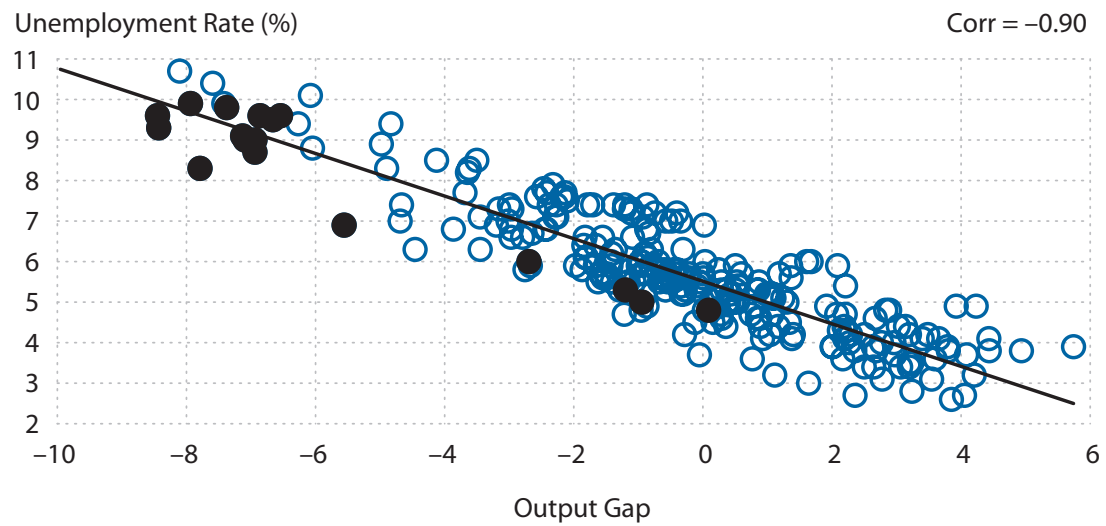

\section{Gap Specification (BP Filter)}

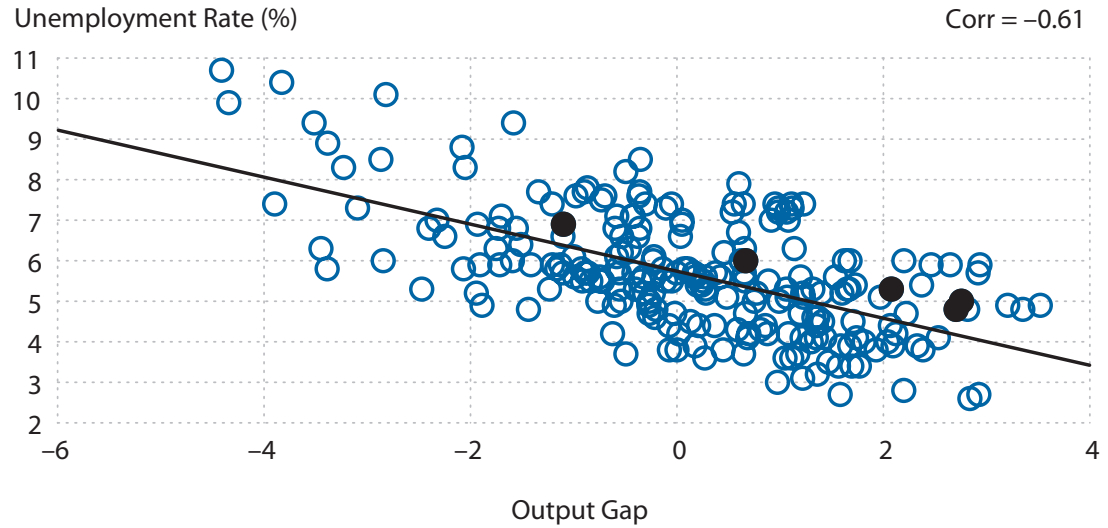

NOTE: The solid black circles indicate the observations since the Great Recession (2007:Q4-2011:Q4). 
In line with the first approach of incorporating the recession dates directly, we first augment the regressions in equations (1), (2), and (4) with recession dummies and an interaction term of recession dummies with the output variables. The dummies are constructed to correspond to the recession dates defined by the National Bureau of Economic Research (NBER) and take values of 1 for the period that starts at the quarter after the peak of a recession and ends at the quarter of the trough. The dummy variables take a value of 0 otherwise. $\underline{8}$

We augment our three benchmark specifications with recession dummies as follows:

$$
\begin{gathered}
\Delta u_{t}=\alpha^{d}+\beta^{d} \Delta y_{t}+\lambda_{1}^{d} d_{t}+\lambda_{2}^{d} d_{t} \Delta y_{t}+e_{t}^{d}, \\
u_{t}=\alpha^{g}+\beta^{g} y_{t}^{g}+\lambda_{1}^{g} d_{t}+\lambda_{2}^{g} d_{t} y_{t}+e_{t}^{g}, \\
\Delta u_{t}=\alpha^{l}+\beta^{l} \Delta y_{t}+\beta_{1}^{l} \Delta y_{t-1}+\beta_{2}^{l} \Delta y_{t-2}+\gamma_{1}^{l} \Delta u_{t-1}+\gamma_{2}^{l} \Delta u_{t-2}+\lambda_{1}^{l} d_{t}+\lambda_{2}^{l} d_{t} \Delta y_{t}+e_{t}^{l} .
\end{gathered}
$$

We further assess the deviations from Okun's law during (i) the past three U.S. recessions and (ii) the Great Recession. To do so, we modify equations (5) through (7) by including two separate dummy variables indicating the historic recessions and either (i) the past three U.S. recessions or (ii) the Great Recession. That is, we split the dummy variable $d_{t}$ further, such that $d_{t}^{c}=1$ captures either the past three U.S. recessions or the Great Recession depending on the specification and $d_{t}^{c}=0$ otherwise. The remaining historic recessions are captured by setting $d_{t}^{h}=1$; this variable has a default value of 0 otherwise. For brevity, we show the modified regression equation only for the difference specification in equation (8). The remaining specifications are adjusted accordingly:

$$
\Delta u_{t}=\alpha^{d}+\beta^{d} \Delta y_{t}+\theta_{1}^{d} d_{t}^{h}+\theta_{2}^{d} d_{t}^{h} \Delta y_{t}+\varphi_{1}^{d} d_{t}^{c}+\varphi_{2}^{d} d_{t}^{c} \Delta y_{t}+e_{t}^{d}
$$

We start with the estimation of various specifications of Okun's law described by equations (1), (2), and (4). We then test for a single endogenous structural break by applying the supremum test of Andrews (1993) to determine whether there is a structural break in the mean of the unemployment rate as well as Okun's coefficient. We then proceed with quantifying the potential shifts in the mean and the slope coefficients of Okun's law during the recessions by estimating equations (5) through (7). We further entertain the possibility that the Great Recession and the past three recessions have been significantly different from the historic ones. Finally, we shed some light on the behavior of Okun's law if the unemployment rate of the labor force aged 20 years and older is used instead of the total civilian unemployment rate. In all estimations conducted, we construct the variance of the parameter estimates using a heteroskedasticity autocorrelation-consistent asymptotic variance estimator. ${ }^{-}$Confidence bands are formed under a normality assumption on the error terms.

\section{RESULTS}

This section provides the results for our various specifications of Okun's law. We provide full-sample estimates, as well as rolling estimates, of Okun's law to assess the extent of time vari- 


\section{Owyang and Sekhposyan}

ation over the observed history. It should be noted that the rolling coefficients capture the changes in correlation and the time of their occurrence in a smooth manner; thus, the magnitudes and the timings of shifts in the mean and slope coefficients should be interpreted in that light. In addition, we interpret the evidence of rolling coefficients outside the confidence bands suggested by the full-sample estimates as indicative of significant shifts in the estimated coefficients. In order to understand the exact timing of the shifts, we conduct formal tests of structural breaks. Furthermore, we include dummy variables capturing the recession periods in U.S. economic history to determine how the recessions alter the behavior of Okun's law. We also separate the dummy variables capturing the historic recessions, the past three recessions, and the Great Recession to understand whether the jobless recovery phenomenon is apparent in Okun's law or whether the Great Recession is indeed all that different from other recessions.

\section{Difference Specification}

Figure 3 plots the rolling estimates (with a 12-year window) of the mean and slope coefficients in equation (1). In addition, the figure depicts the respective coefficients obtained using the full sample of data-that is, the average correlation between changes in the unemployment rate and output growth and its 95 percent confidence bands.

The fluctuations in the rolling window parameter estimates suggest that the relationship expressed by Okun's law has not been stable over time. Significant changes in both the mean unemployment rate fluctuations and the slope coefficient occur over time. It appears that the mean unemployment rate was historically low around 1975, and then again between 1995 and 2007.

The slope coefficient also exhibits considerable variations over time. The estimation through the rolling windows captures breakdowns in the slope coefficient during the recessions of the early 1970s, 1980s, 2000s, as well as the Great Recession. The significant changes in the correlation occurred from 1965 to 1975 and during the 1990s and the Great Recession. The correlation between changes in the unemployment rate and output growth decreased significantly between 1965 and 1975. It since has increased significantly in the 1990s and then during the Great Recession. For example, before the Great Recession, a 1-percentage-point increase in output growth would be associated with a decrease in the unemployment rate of about 0.15 percentage points. After the recession, the same change in output growth would be associated with a decrease in the unemployment rate of about 0.34 percentage points. In addition, the most recent value of the rolling estimate falls outside the 95 percent confidence bands around the full-sample coefficient estimate; this provides statistically significant evidence that the Great Recession intensified the unemployment rate-output growth relationship compared with an average historic recession.

However, the breakdown detected during the Great Recession is not the most severe one over the historical sample. For example, the correlation coefficient pre-Great Recession is similar to 1975 's and the correlation coefficient post-Great Recession is similar to 1995's. Interestingly, when the time variation in the mean and the slope coefficient are compared, they appear to be moving in the same direction (in absolute terms): When the average changes in the unemployment rate are high, the sensitivity of the unemployment rate to output growth fluctuations is also high and vice versa. 


\section{Figure 3}

\section{Okun's Law in Difference Specification with Rolling Windows}

\section{A. Mean Coefficient}

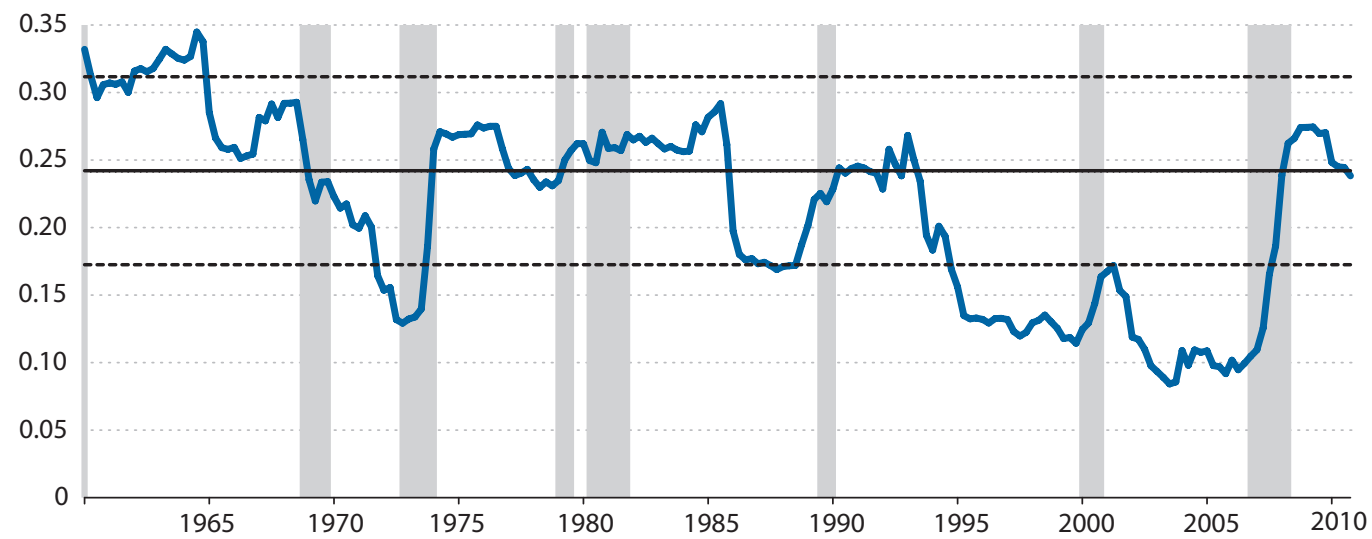

\section{B. Slope Coefficient}

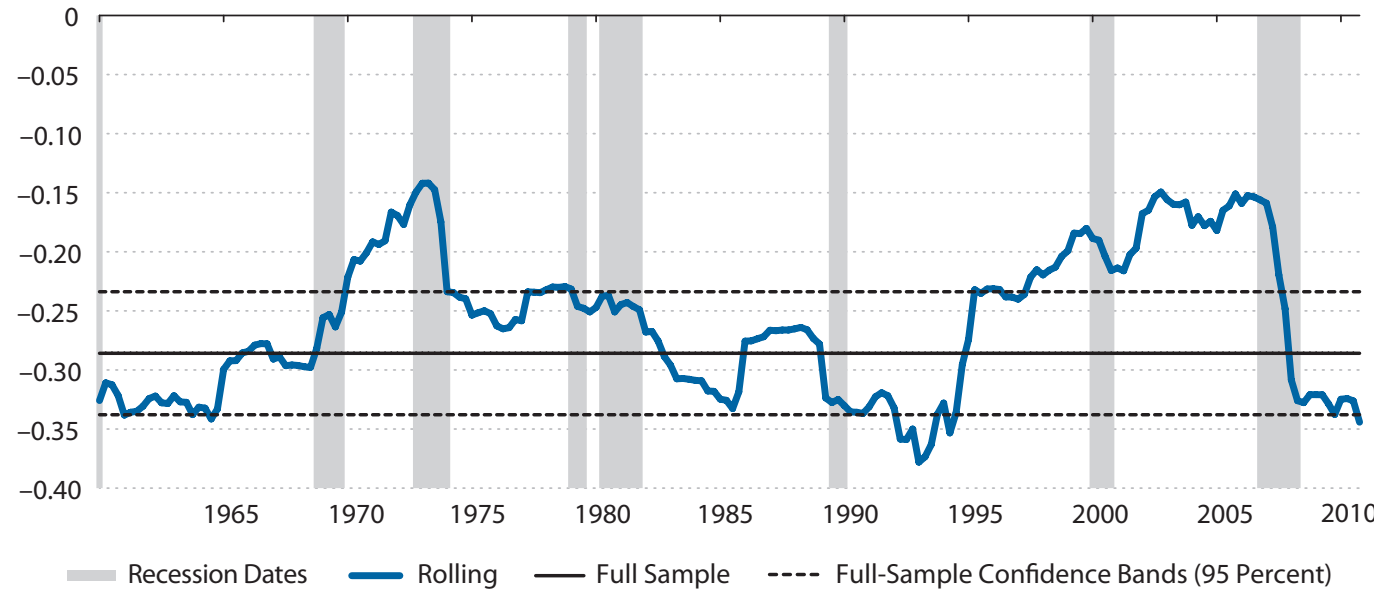

Table 1 reports single unknown structural break test results using the methodology of Andrews (1993). There is a significant breakdown in the correlation associated with the end of a recession dating to 1983:Q1 at the 10 percent significance level. When we test for a break in the mean or in the joint dynamics of the mean and slope coefficients, we find no signficant breaks. Structural break tests of the considered form, however, are generally poor at detecting breaks near sample endpoints; results for these tests may change as more data become available.

Table 2 presents the results of the formal hypothesis tests. The average change in the unemployment rate is 0.24 percentage points. The sensitivity of the unemployment rate to output growth fluctuations is about 0.29 percentage points. Both coefficients are statistically different from zero. We then allow Okun's law to differ both in the level and the slope in the recessions. The estimates show that in an average recession the unemployment rate fluctuations are 0.41 


\section{Owyang and Sekhposyan}

\section{Table 1}

\section{Andrews' (1993) Quandt Likelihood Ratio Structural Break Test}

\begin{tabular}{|c|c|c|c|c|c|c|c|c|c|}
\hline \multirow[b]{2}{*}{ Specification } & \multicolumn{3}{|c|}{ Break in mean } & \multicolumn{3}{|c|}{ Break in slope } & \multicolumn{3}{|c|}{ Break in both } \\
\hline & QLR Statistic & $p$-Value & Break & QLR Statistic & $p$-Value & Break & QLR Statistic & $p$-Value & Break \\
\hline Difference & 9.03 & 0.11 & 1983:Q1 & 10.12 & 0.07 & 1983:Q1 & 9.50 & 0.19 & 1983:Q1 \\
\hline Gap (CBO) & 20.75 & 0.00 & 1958:Q3 & 10.34 & 0.07 & 1975:Q1 & 27.22 & 0.00 & 1958:Q3 \\
\hline Gap (BP filter) & 39.89 & 0.00 & 1972:Q2 & 1.84 & 1.00 & 1970:Q1 & 38.84 & 0.00 & 1972:Q2 \\
\hline Dynamic & 20.86 & 0.00 & 1973:Q3 & 47.94 & 0.00 & 2002:Q3 & 41.58 & 0.00 & 2000:Q4 \\
\hline
\end{tabular}

NOTE: The Quandt likelihood ratio (QLR) break test is a test for an unknown breakpoint in all or a subset of regression parameters. The reported results test for a break in the mean, the slope coefficients, and both of them jointly. For the dynamic specification, we test for a break in the mean, three slope coefficients associated with output growth (jointly), in addition to testing for a break in both of them together.

\section{Table 2}

\section{Regression Coefficients for Difference Specification}

\begin{tabular}{|c|c|c|c|c|c|c|c|c|}
\hline Specification & $\alpha$ & $\beta$ & $\lambda_{1}$ & $\lambda_{2}$ & $\theta_{1}$ & $\theta_{2}$ & $\phi_{1}$ & $\phi_{2}$ \\
\hline Benchmark & $0.24^{* *}$ & $-0.29 * *$ & - & - & - & - & - & - \\
\hline Benchmark with all recession dates & $0.06^{* *}$ & $-0.17^{* *}$ & $0.41^{* *}$ & -0.06 & - & - & - & - \\
\hline Benchmark with split recession dates (I) & $0.06^{* *}$ & $-0.17^{* *}$ & - & - & $0.43^{* *}$ & -0.05 & $0.35^{* *}$ & $-0.11^{*}$ \\
\hline Benchmark with split recession dates (II) & $0.06^{* *}$ & $-0.17^{* *}$ & - & - & $0.42^{* *}$ & -0.04 & $0.37^{* *}$ & $-0.16^{* *}$ \\
\hline
\end{tabular}

NOTE: Specification I (II) corresponds to the marginal effects of the three most recent U.S. recessions (Great Recession) considered separately from the historic ones. Split recession specifications: I, Wald test statistic for $\left(\theta_{1}=\phi_{1}\right.$ and $\left.\theta_{2}=\phi_{2}\right)=1.35 ; p$-value $=0.51$. II, Wald test statistic for $\left(\theta_{1}=\phi_{1}\right.$ and $\left.\theta_{2}=\phi_{2}\right)=2.72 ; p$-value $=0.26$. The total number of observations is 251 ; the number of observations in recessions is 51 .

** and ${ }^{*}$ indicate significance at the 5 and 10 percent levels, respectively.

percentage points higher relative to the expansion periods; this observed difference is significant. In addition, the unemployment rate becomes more sensitive to fluctuations in output growth, though the increase in the correlation is not significant.

When we separate the historical recessions from the three most recent recessions (benchmark I in Table 2) and the Great Recession (benchmark II in the table), there appear to be significant changes in the mean unemployment rate fluctuations in all recessions despite the specification. In this regard, the past three recessions and the Great Recession do not differ from one another or from the historic ones in magnitude and significance. In addition, it appears that the average historic recessions do not significantly alter the slope of Okun's law; however, we detect significant changes in the correlation between changes in the unemployment rate and output growth during both the past three recessions and the Great Recession. $\frac{10}{}$ For every 1 percentage-point decrease in output growth during the past three recessions, the unemployment rate has increased by 0.11 percentage points. During the Great Recession the increase was magnified to 0.16 percentage points. A Wald test, however, suggests that the marginal impact of the three most recent U.S. recessions and the Great Recession is not statistically different from the impact of the historic ones. 


\section{Figure 4}

\section{Okun's Law in Gap Specification (CBO) with Rolling Windows}

\section{A. Mean Coefficient}

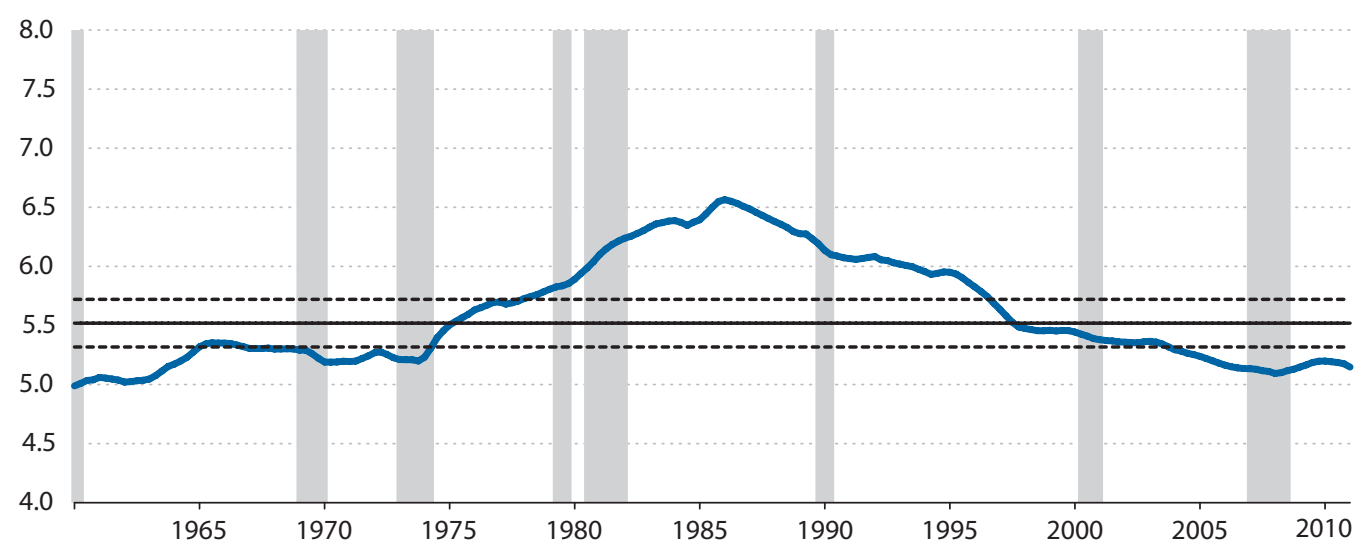

B. Slope Coefficient

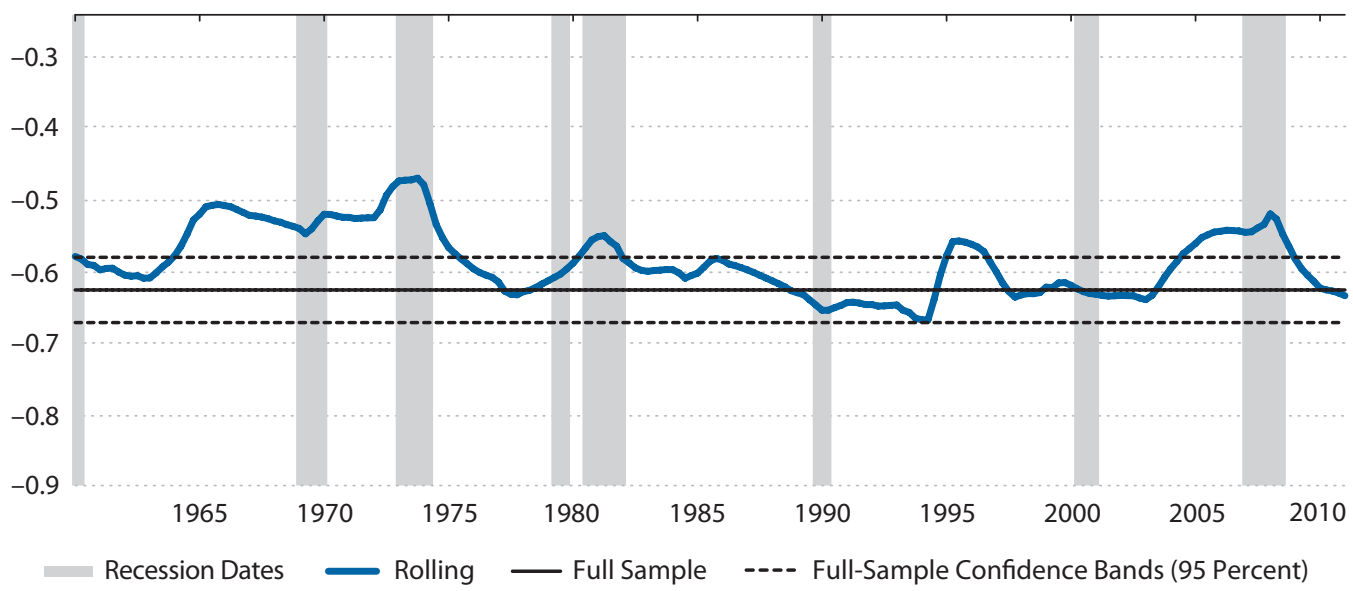

In summary, we detect significant variations in the Okun's law relationship over the business cycle. In general, when the average unemployment rate fluctuations are high, the unemployment rate is also more sensitive to output growth variations. All recessions seem to significantly alter the average unemployment rate fluctuations. The three most recent recessions, as well as the Great Recession, seem to significantly change the sensitivity of the unemployment rate to output growth as well.

\section{Gap Specification}

We first discuss the results for Okun's law in the gap specification, equation (2), where the output gap is consistent with the $\mathrm{CBO}$ estimate. Then we proceed with results for the estimate obtained for the output gap with a BP filter. 


\section{Owyang and Sekhposyan}

\section{Table 3}

\section{Regression Coefficients for Gap Specification (CBO)}

\begin{tabular}{|c|c|c|c|c|c|c|c|c|}
\hline Specification & $\alpha$ & $\beta$ & $\lambda_{1}$ & $\lambda_{2}$ & $\theta_{1}$ & $\theta_{2}$ & $\phi_{1}$ & $\phi_{2}$ \\
\hline Benchmark & $5.52^{* * *}$ & $-0.53^{* *}$ & - & - & - & - & - & - \\
\hline Benchmark with all recession dates & $5.65^{* *}$ & $-0.55^{* *}$ & $-0.75^{* *}$ & -0.02 & - & - & - & - \\
\hline Benchmark with split recession dates (I) & $5.65^{* *}$ & $-0.54^{* *}$ & - & - & $-0.79 * *$ & -0.08 & $-0.69 * *$ & $0.09^{* *}$ \\
\hline Benchmark with split recession dates (II) & $5.65^{* *}$ & $-0.55^{* *}$ & - & - & $-0.73 * *$ & -0.07 & $-1.01^{* *}$ & 0.06 \\
\hline
\end{tabular}

NOTE: Specification I (II) corresponds to the marginal effects of the three most recent U.S. recessions (Great Recession) considered separately from the historic ones. Split recession specifications: I, Wald test statistic for $\left(\theta_{1}=\phi_{1}\right.$ and $\left.\theta_{2}=\phi_{2}\right)=8.14 ; p$-value $=0.02$. II, Wald test statistic for $\left(\theta_{1}=\phi_{1}\right.$ and $\left.\theta_{2}=\phi_{2}\right)=10.87 ; p$-value $=0.01$. The total number of observations is 252 ; the number of observations in recessions is 52 .

** indicates significance at the 5 percent level.

Figure 4 depicts the rolling window estimates of the mean and slope coefficients in the $\mathrm{CBO}$ gap specification and shows significant fluctuations in both coefficients over time. However, the mean of the unemployment rate appears to be changing in a rather smooth and persistent manner. Though the average unemployment rate is about 5.5 percent over the full sample, it is significantly higher during the period between the late 1970s and the late 1990s, reaching a peak of about 6.5 percent around 1987. The slope coefficient also exhibits time variation. It appears that the drastic changes in Okun's correlation coefficient also occur mostly around the recessions, with the shift in the mid-1990s an exception to that rule. The overall trend observed in Figure 3 (the difference specification) holds in this setup as well. Periods of high unemployment seem to coincide with periods of higher correlation between the unemployment rate and the output gap.

The most recent significant shift in the slope coefficient occurs around the Great Recession. Prior to this recession a 1-percentage-point increase in the output gap decreased the unemployment rate by roughly 0.42 percentage points, while after the recession this correlation is closer to its historical average of about -0.55 percentage points. However, the shift in the slope coefficient observed in the late 1970s is by far larger than that during the Great Recession. The structural break tests in Table 1 suggest a significant break date in the mean for 1958:Q3, while the break in the slope coefficient is less significant (only at the 10 percent significance level) dating to 1975:Q1. The break in the joint relationship (i.e., the overall behavior of Okun's law) coincides with the break date of the mean. It should be noted that 1958:Q3 and 1975:Q1 are only one quarter after a recession.

Table 3 shows the regression coefficients for the $\mathrm{CBO}$ gap specification. The average unemployment rate over the full sample is about 5.52 percent and is statistically different from zero. A 1-percentage-point increase in the output gap decreases the unemployment rate by 0.53 percentage points. When the effects of recessions are captured by incorporating a recession dummy and an interaction term of a recession dummy with the output gap, we find that the average unemployment rate is statistically lower during recessions by 0.75 percentage points. The recessions do not seem to alter the sensitivity of the unemployment rate to output gap fluctuations on average. 


\section{Figure 5}

\section{Okun's Law in Gap Specification (BP Filter) with Rolling Windows}

\section{A. Mean Coefficient}

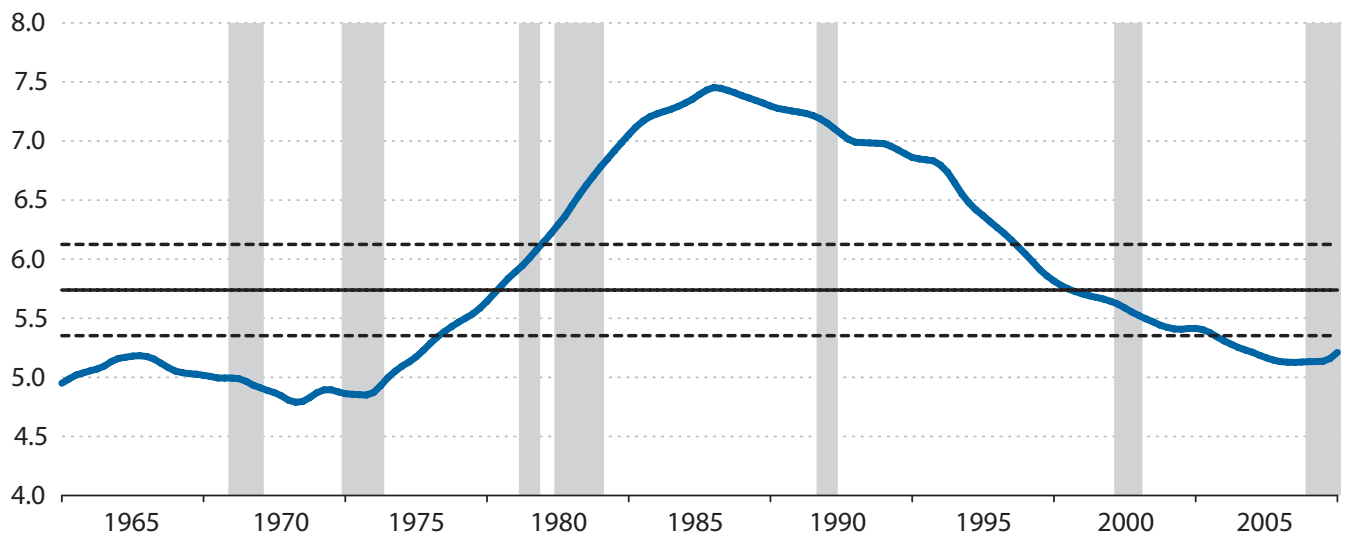

\section{B. Slope Coefficient}

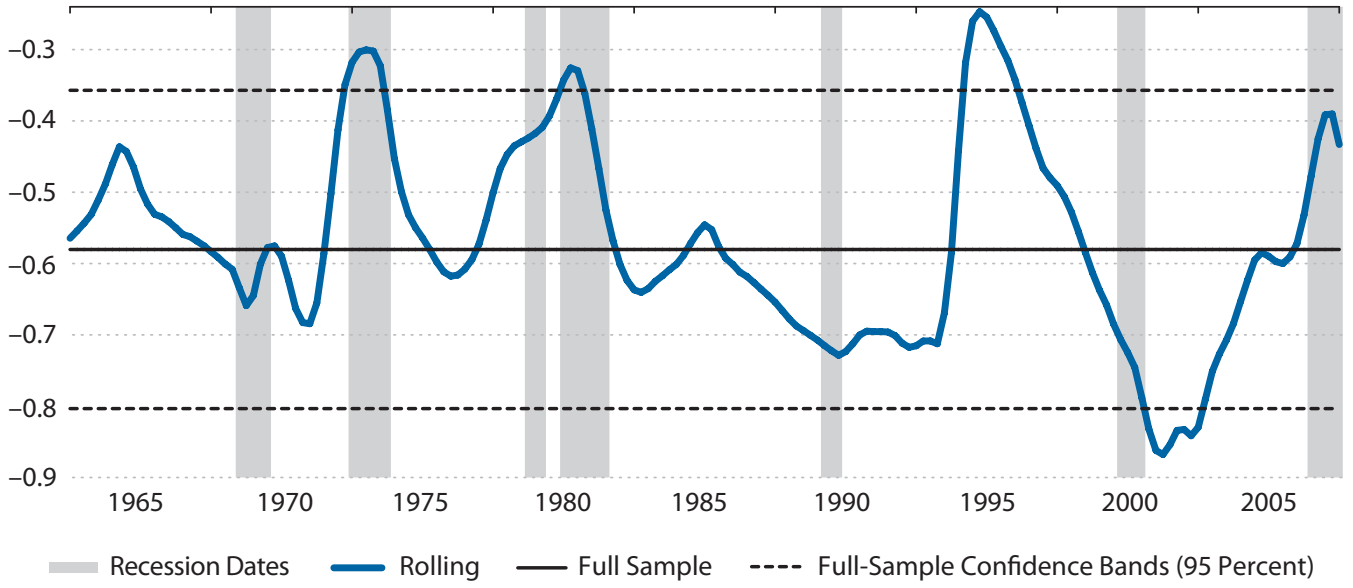

When we separate the past three recessions and the Great Recession from the rest of the recorded U.S. recessions, the significant difference in the mean unemployment rate during the recessions still holds. However, during the Great Recession the shift in the mean is considerably larger in magnitude: about 0.28 percentage points lower relative to historic recessions. The past three recessions seem to have significantly altered Okun's correlation coefficient as well: It has decreased (in absolute terms) by 0.09 percentage points. The Wald test results suggest significant evidence that Okun's law has been statistically different from its historical pattern in both the three most recent recessions and the Great Recession.

The results for Okun's law based on the output gap measure obtained with the BP filter are qualitatively similar to those based on the CBO measure of the output gap. Since we use a centered BP filter, we lose three quarters of data from the Great Recession era, as they are used in 


\section{Owyang and Sekhposyan}

\section{Table 4}

\section{Regression Coefficients for Gap Specification (BP Filter)}

\begin{tabular}{|c|c|c|c|c|c|c|c|c|}
\hline Specification & $\alpha$ & $\beta$ & $\lambda_{1}$ & $\lambda_{2}$ & $\theta_{1}$ & $\theta_{2}$ & $\phi_{1}$ & $\phi_{2}$ \\
\hline Benchmark & $5.74^{* *}$ & $-0.58^{* *}$ & - & - & - & - & - & - \\
\hline Benchmark with all recession dates & $5.78^{* *}$ & $-0.61^{* *}$ & -0.16 & 0.05 & - & - & - & - \\
\hline Benchmark with split recession dates (I) & $5.78^{* *}$ & $-0.61^{* *}$ & - & - & -0.27 & 0.00 & -0.13 & 0.25 \\
\hline Benchmark with split recession dates (II) & $5.78^{* *}$ & $-0.61^{* *}$ & - & - & -0.31 & -0.01 & $0.56^{* *}$ & 0.09 \\
\hline
\end{tabular}

NOTE: Specification I (II) corresponds to the marginal effects of the three most recent U.S. recessions (Great Recession) considered separately from the historic ones. Split recession specifications: I, Wald test statistic for $\left(\theta_{1}=\phi_{1}\right.$ and $\left.\theta_{2}=\phi_{2}\right)=1.67 ; p$-value $=0.43$. II, Wald test statistic for $\left(\theta_{1}=\phi_{1}\right.$ and $\left.\theta_{2}=\phi_{2}\right)=4.08 ; p$-value $=0.13$. The total number of observations is 228 ; the number of observations in recessions is 46 .

** indicates significance at the 5 percent level.

estimating the output gap. Figure 5 highlights the similarity in the dynamics of Okun's coefficient. The estimated mean unemployment rate still fluctuates in a very smooth fashion. There are significant shifts in the slope coefficient, with the largest shift in magnitude during the late 1990s. The difference in the estimates based on the two measures of the output gap is in the magnitudes. Though the full-sample estimates of the mean and slope coefficients are roughly the same, the fluctuations in the rolling window estimates are much larger in magnitude for the output gap measure obtained with a BP filter. The formal structural break tests in Table 1 suggest a significant break in the mean coefficient but not the slope, which is in line with the results based on the $\mathrm{CBO}$ estimate of the output gap. However, the break date for the Okun's law relationship corresponds to 1972:Q2.

Table 4 shows parameter estimates for the BP-filtered full sample that are very similar to those for the CBO's output gap measure. The average sensitivity, as well as sensitivities over recessions, are marginally higher for this specification relative to those obtained using the CBO's output gap measure. On the other hand, the recessions seem to be associated with a smaller decline in the average unemployment rate in this case. Nevertheless, the results are generally not statistically significant. The only exception is the effect of the Great Recession on the average unemployment rate: The average unemployment rate increased by about 0.56 percentage points during this time. Yet, there is no statistically significant evidence that either the past three U.S. recessions or the Great Recession are statistically different from the historic ones based on this specification.

We conclude that the gap specification of Okun's law is also affected by instabilities. The mean seems to change in a persistent manner and is lower during recessions. Overall, recessions do not significantly alter the correlation between the unemployment rate and the output gap. In general, the two measures of the output gap do not appear to yield qualitatively different results.

Certainly, the discussion of this specification comes with a caveat that we use an estimated regressor-the output gap-but we do not correct for the additional uncertainty this introduces to the estimation. In essence, the degree of uncertainty in this model is underestimated. Moreover, the computation of the output gap itself can be important in interpreting the results of Okun's regression. 
Owyang and Sekhposyan

\section{Table 5}

\section{Regression Coefficients for Dynamic Specification}

\begin{tabular}{|c|c|c|c|c|c|c|c|c|c|c|c|c|}
\hline Specification & $\alpha$ & $\beta$ & $\beta_{1}$ & $\beta_{2}$ & $\gamma_{1}$ & $\gamma_{2}$ & $\lambda_{1}$ & $\lambda_{2}$ & $\theta_{1}$ & $\theta_{2}$ & $\phi_{1}$ & $\phi_{2}$ \\
\hline Benchmark & $0.28^{* *}$ & $-0.21^{* *}$ & $-0.09^{* *}$ & $-0.05^{* *}$ & $0.24^{* *}$ & -0.08 & - & - & - & - & - & - \\
\hline $\begin{array}{l}\text { Benchmark with all } \\
\text { recession dates }\end{array}$ & $0.17^{* *}$ & $-0.14^{* *}$ & $-0.08^{* *}$ & $-0.05^{* *}$ & $0.21^{* *}$ & -0.10 & $0.22 * *$ & $-0.11^{* *}$ & - & - & - & - \\
\hline $\begin{array}{l}\text { Benchmark with split } \\
\text { recession dates (I) }\end{array}$ & $0.17^{* *}$ & $-0.14^{* *}$ & $-0.08^{* *}$ & $-0.05^{* *}$ & $0.21^{* *}$ & -0.10 & - & - & $0.23^{* *}$ & $-0.12^{* *}$ & $0.21 * *$ & -0.08 \\
\hline $\begin{array}{l}\text { Benchmark with split } \\
\text { recession dates (II) }\end{array}$ & $0.17^{* *}$ & $-0.14^{* *}$ & $-0.08^{* *}$ & $-0.05^{* *}$ & $0.21^{* *}$ & -0.10 & - & - & $0.23^{* *}$ & $-0.11^{* *}$ & $0.18^{* *}$ & $-0.12^{* *}$ \\
\hline
\end{tabular}

NOTE: Specification I (II) corresponds to the marginal effects of the three most recent U.S. recessions (Great Recession) considered separately from the historic ones. Split recession specifications: I, Wald test statistic for $\left(\theta_{1}=\phi_{1}\right.$ and $\left.\theta_{2}=\phi_{2}\right)=0.88$; $p$-value $=0.65$. II, Wald test statistic for $\left(\theta_{1}=\phi_{1}\right.$ and $\left.\theta_{2}=\phi_{2}\right)=0.59 ; p$-value $=0.74$. The total number of observations is 249 ; the number of observations in recessions is 49 .

** and * indicate significance at the 5 and 10 percent levels, respectively.

\section{Dynamic Specification}

Table 5 shows the regression coefficients for the dynamic specification. The inclusion of lags increases the mean and the overall correlation between changes in the unemployment rate and output growth relative to the difference specification (see Table 2). Based on the dynamic specification the average fluctuation in the unemployment rate is 0.28 percentage points, while a 1-percentage-point increase in the output growth decreases the unemployment rate by a total of 0.35 percentage points.

In contrast to the results in the difference specification, it appears that the effects of the recessions arise from the shifts in the mean and the slope. An average recession increases the unemployment rate by 0.22 percentage points, slightly lower than the 0.41 -percentage-point estimate based on the difference specification. The effect of the past three recessions and the Great Recession do not appear to differ from those of historic recessions by their estimated shifts in the mean and the slope of Okun's law. However, these recessions seem to have significantly altered the correlation coefficient relative to historic recessions: Okun's correlation coefficient decreased by 0.12 percentage points during the Great Recession, while the reduction was about 0.11 percentage points for the previous U.S. recessions.

The rolling estimates of the regression coefficient of the contemporaneous output growth and its two lags indicate time variation. Figure 6 shows the rolling window estimates of the mean and the correlation coefficients of the contemporaneous and lagged output growth together with the full-sample estimates. We observe significant time variation in all the coefficients. The changes in the average unemployment rate fluctuations and the contemporaneous correlation coefficient show dynamics similar to the difference specification: When changes in the unemployment rate are high, the unemployment rate is more sensitive to fluctuations in output growth. The dynamics of the lagged correlation coefficients are more persistent. The structural break tests in Table 1 attribute the breaks in the mean to 1973:Q3; the breaks in the slope and the joint dynamics are attributed to the early 2000 s. 


\section{Owyang and Sekhposyan}

\section{Figure 6}

\section{Okun's Law in Dynamic Specification with Rolling Windows}

\section{A. Mean Coefficient}

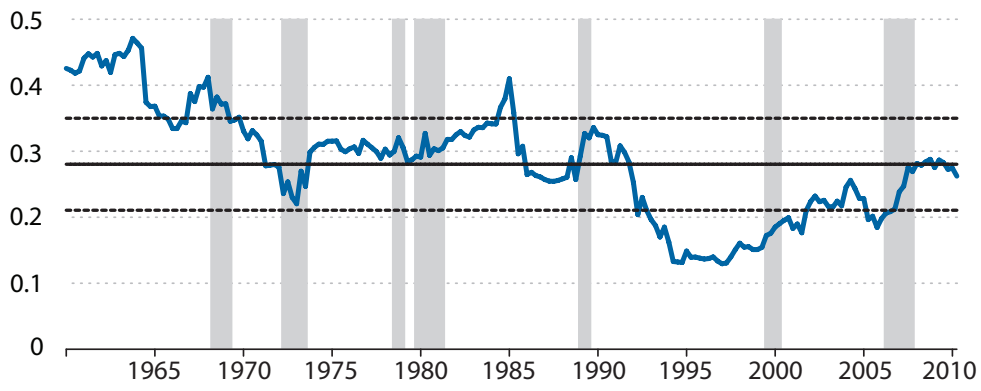

B. Slope Coefficient: $\operatorname{Lag}(1)$

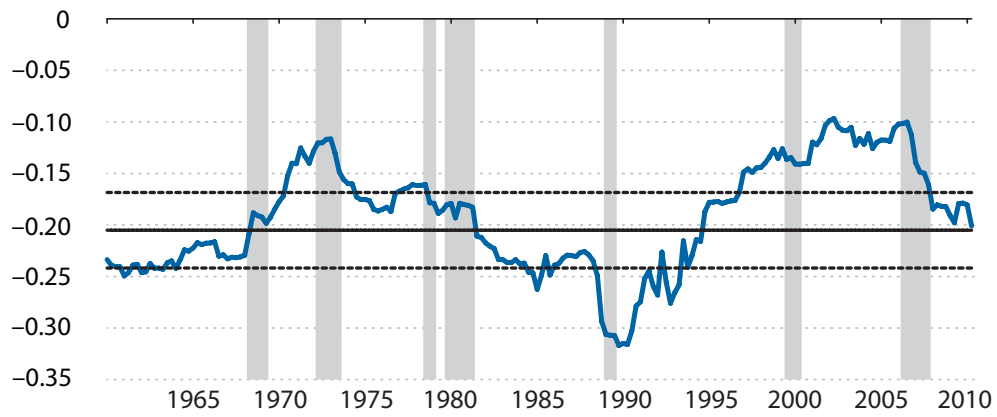

C. Slope Coefficient: Lag(2)

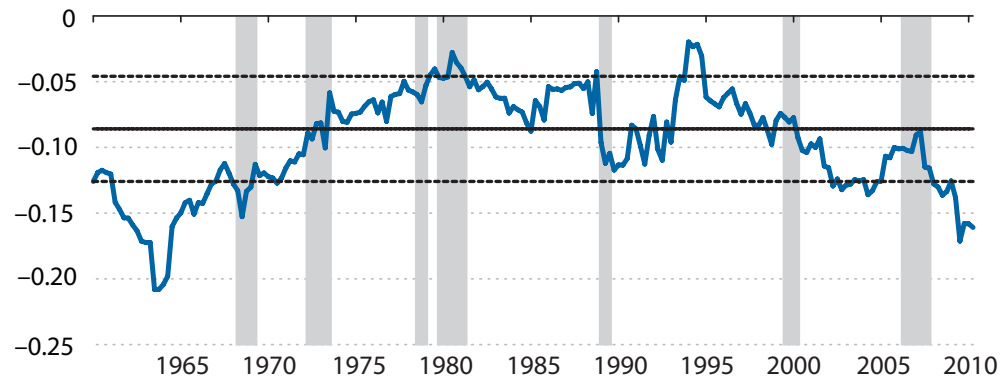

D. Slope Coefficient: Lag(3)

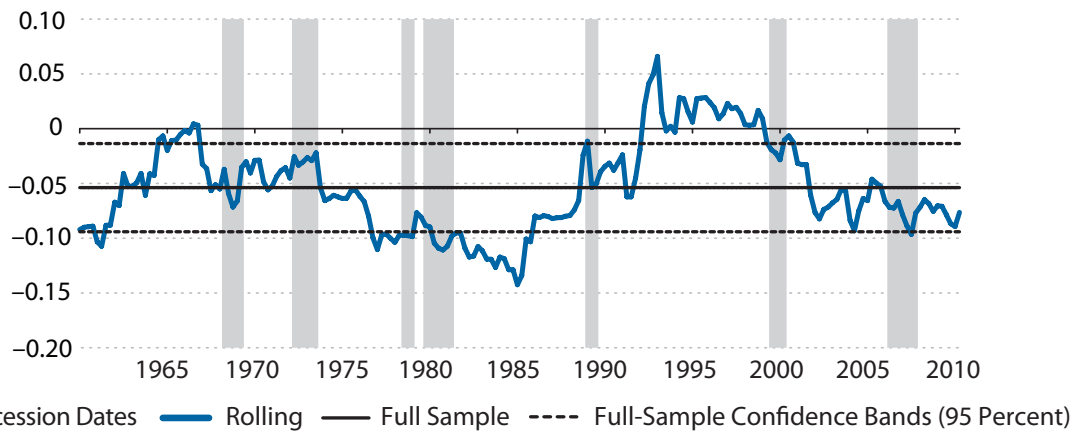




\section{Figure 7}

\section{Okun's Law in Difference Specification with Unemployment Rate for Labor Force Aged 20 Years and Older}

\section{A. Mean Coefficient}

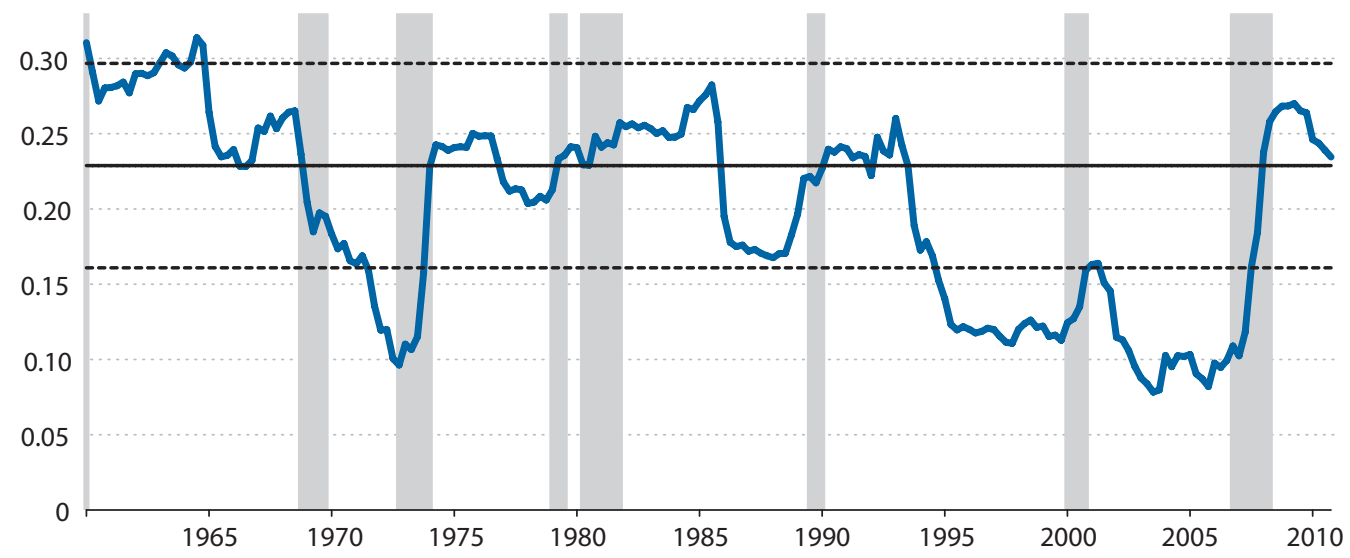

\section{B. Slope Coefficient}

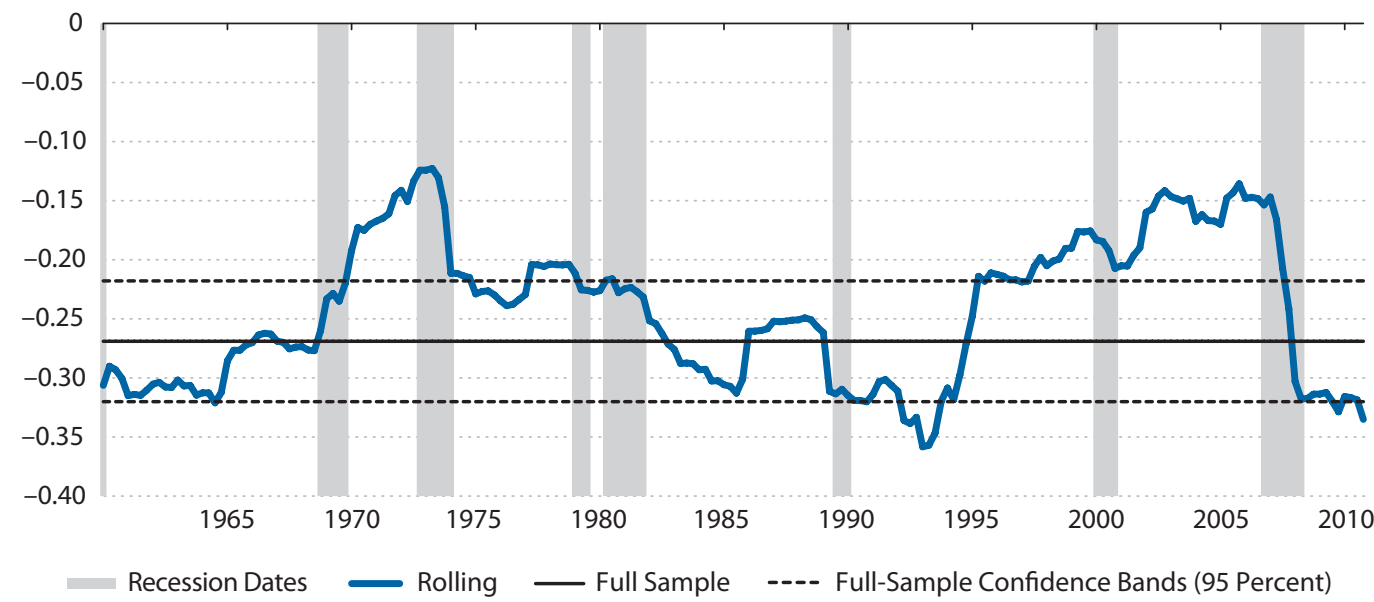

\section{Robustness}

In order to consider the robustness of our results to the different measures of unemployment we consider Okun's law using not the civilian unemployment rate, but the unemployment rate of the labor force aged 20 years and older (series ID LNS14000024 from the FRED database).

Figure 7 depicts the rolling estimates of the mean and slope coefficients in the difference specification as in equation (1) for this new measure of the unemployment rate. The pattern of the figures are similar to that of the difference specification with the civilian unemployment rate (see Figure 3). Average unemployment rate fluctuations for the labor force aged 20 years and older are about 0.22 percentage points compared with 0.24 percentage points in the civilian unemployment rate. The average slope coefficient is slightly lower (in absolute value) for the 


\section{Owyang and Sekhposyan}

\section{Table 6}

Regression Coefficients for Difference Specification with Unemployment Rate for Workforce 20 Years and Older

\begin{tabular}{|c|c|c|c|c|c|c|c|c|}
\hline Specification & $\alpha$ & $\beta$ & $\lambda_{1}$ & $\lambda_{2}$ & $\theta_{1}$ & $\theta_{2}$ & $\phi_{1}$ & $\phi_{2}$ \\
\hline Benchmark & $0.22^{* *}$ & $-0.27^{* *}$ & - & - & - & - & - & - \\
\hline Benchmark with all recession dates & $0.05^{* *}$ & $-0.16^{* *}$ & $0.40^{* * *}$ & -0.05 & - & - & - & - \\
\hline Benchmark with split recession dates (I) & $0.05^{* *}$ & $-0.16^{* *}$ & - & - & $0.42^{* *}$ & -0.03 & $0.34^{* *}$ & $-0.12^{* *}$ \\
\hline Benchmark with split recession dates (II) & $0.05^{* *}$ & $-0.16^{* *}$ & - & - & $0.40^{* *}$ & -0.02 & $0.36^{* *}$ & $-0.16^{* *}$ \\
\hline
\end{tabular}

NOTE: Specification I (II) corresponds to the marginal effects of the three most recent U.S. recessions (Great Recession) considered separately from the historic ones. Split recession specifications: I, Wald test statistic for $\left(\theta_{1}=\phi_{1}\right.$ and $\left.\theta_{2}=\phi_{2}\right)=1.99 ; p$-value $=0.37$. II, Wald test statistic for $\left(\theta_{1}=\phi_{1}\right.$ and $\left.\theta_{2}=\phi_{2}\right)=4.30 ; p$-value $=0.12$. The total number of observations is 251 ; the number of observations in recessions is 51 .

** indicates significance at the 5 percent level.

labor force aged 20 years and older: A 1-percentage-point increase in the output growth decreases unemployment rate by 0.27 percentage points compared with the 0.29 percentage points of the difference specification. Thus, the unemployment rate for this demographic group seems to be lower on average and less sensitive to the output growth fluctuations. There is considerable time variation in both the mean and the slope. Relative to the civilian unemployment rate, the mean is lower for the period prior to 1983. In addition, the unemployment rate for the labor force aged 20 years and older has been less sensitive to the output growth fluctuations in general, though the difference has narrowed over the last decade such that its correlation with output growth is still similar to the 0.34 -percentage-point correlation between the civilian unemployment rate and output growth at the end of the sample.

Table 6 shows the regression coefficients for the difference specification of Okun's law for the labor force aged 20 years and older. The results suggest, again, that recessions tend to significantly alter the average unemployment rate fluctuations compared with changes in the slope. However, the Great Recession and the three most recent U.S. recessions with documented jobless recoveries appear to also affect the slope coefficients in a statistically significant way.

\section{CONCLUSION}

We consider various specifications of Okun's law to assess the degree of time variation in the unemployment and output fluctuations over the business cycle. We pay particular attention to the three most recent U.S. recessions and the Great Recession. We find a great degree of instability in the historical performance of Okun's law. The breakdowns in Okun's law seem to be highly correlated with the business cycle: The detected break dates of the largest changes in the coefficients appear to be around recessions. The most robust finding of this study is that recessions contribute to the increase in the unemployment rate on average. The correlation between unemployment and output fluctuations changes significantly during the Great Recession and the three most recent recessions. The statistical significance of the slope changes depends on the specification at hand. Nevertheless, it appears that periods of high unemployment are correlated with increased sensitivity of the unemployment rate to output growth or gap fluctua- 


\section{Owyang and Sekhposyan}

tions, though these shifts might not always result in significant changes. We conclude by suggesting that back-of-the-envelope calculations used to relate changes in the unemployment rate to changes in output growth or the output gap should not be taken too seriously but rather as an approximation to be taken with a grain of salt.

\section{NOTES}

1 At different points in time, scholars have used either gross domestic product (GDP) or gross national product (GNP) to measure output. Since 1992, there has been more emphasis on GDP as a comprehensive measure of economic activity, and most studies have relied predominantly on GDP since. We do so as well; however, when discussing the literature, we explicitly indicate the measure each study uses.

$\underline{2}$ For example, Mankiw (2002) and Romer (2006) estimate a 2-percentage-point decline in the real GDP growth rate for every percentage-point increase in the unemployment rate, while the original estimate by Okun (1962) is a 3-percentage-point decline.

$\underline{3}$ For a structural interpretation of Okun's law see, for example, Christiano, Trabant, and Wallentin (2010).

4 In his paper, Okun argues that 4 percent unemployment is a reasonable approximation of the NAIRU and fullemployment condition.

$\underline{5}$ The real-time data are from the ArchivaL Federal Reserve Economic Data (ALFRED) database (http://alfred.stlouisfed.org/). The two vintages of GDP growth are for January 27, 2012 (GDPC1 PCH, 2012-01-27) and January 28, 2011 (GDPC1 PCH, 2011-01-28). The vintages for the unemployment rate are for February 3, 2012 (UNRATE, 2012-02-03) and February 4, 2011 (UNRATE, 2011-02-04). The quarterly unemployment rate is constructed by averaging the monthly observations in respective quarters.

$\underline{6}$ The most recent data are available from the FRED database (http://research.stlouisfed.org/fred2/).

$\underline{7}$ We use a symmetrically centered filter with a window of 12; thus, the total number of terms in the band-pass filter is 25 . Since we use a centered filter, we lose 12 observations (the equivalent of 3 years) from each end of the sample. For details, see Baxter and King (1999).

8 The dates are determined by the NBER Business Cycle Dating Committee (dates provided at www.nber.org/cycles.html).

$\underline{9}$ The estimated variance of the error term is obtained as $\hat{\Omega}=\sum_{i=-q(T)}^{q(T)}(1-|i /(q(T)+1)|)(T+1)^{-1} \sum_{t=i+1}^{T}\left(x_{t} \hat{e}_{t}\right)\left(x_{t-i} \hat{e}_{t-i}\right)^{\prime}$ for all $i \geq 0$. We set $q(T)=T^{\frac{1}{3}}$, where $T$ is the effective sample size in each estimation. See Newey and West (1987) for details.

$\underline{10}$ This result could be driven by the Great Recession since it is also included in the three most recent recessions.

\section{REFERENCES}

Andrews, Donald W.K. "Tests for Parameter Instability and Structural Change with Unknown Change Point." Econometrica, July 1993, 61(4), pp. 821-56.

Attfield, Clifford L.F. and Silverstone, Brian. "Okun's Coefficient: A Comment." Review of Economics and Statistics, May 1997, 79(2), pp. 326-29.

Baxter, Marianne and King, Robert G. "Measuring the Business Cycle: Approximate Band-Pass Filters for Economic Time Series." Review of Economics and Statistics, November 1999, 81(4), pp. 575-93.

Beaton, Kimberly. "Time Variation in Okun's Law: A Canada and U.S. Comparison." Bank of Canada Working Paper No. 2010-7, Bank of Canada, 2010; www.bankofcanada.ca/wp-content/uploads/2010/05/wp10-7.pdf.

Christiano, Lawrence J.; Trabandt, Mathias and Walentin, Karl. "Involuntary Unemployment and the Business Cycle." NBER Working Paper No. 15801, National Bureau of Economic Research, March 2010; www.nber.org/papers/w15801.pdf. 


\section{Owyang and Sekhposyan}

Congressional Budget Office. "A Summary of Alternative Methods for Estimating Potential GDP." Background paper, March 2004; www.cbo.gov/sites/default/files/cbofiles/ftpdocs/51xx/doc5191/03-16-gdp.pdf.

Daly, Mary and Hobijn, Bart. "Okun's Law and the Unemployment Surprise of 2009." Federal Reserve Bank of San Francisco Economic Letter, March 8, 2010, No. 2010-7; www.frbsf.org/publications/economics/letter/2010/el2010-07.html.

Engemann, Kristie M. and Owyang, Michael T. "Whatever Happened to the Business Cycle? A Bayesian Analysis of Jobless Recoveries." Macroeconomic Dynamics, November 2010, 14(5), pp. 709-26.

Knotek, Edward S. II. “How Useful Is Okun's Law? Federal Reserve Bank of Kansas City Economic Review, Fourth Quarter 2007, pp. 73-103; www.kc.frb.org/publicat/econrev/PDF/4q07Knotek.pdf.

Mankiw, N. Gregory. Macroeconomics. Fifth Edition. New York: Worth Publishers, 2002.

Newey, Whitney K. and West, Kenneth D. "A Simple, Positive Semi-Definite, Heteroskedasticity and Autocorrelation Consistent Covariance Matrix." Econometrica, May 1987, 55(3), pp. 703-08.

Okun, Arthur M. "Potential GNP: Its Measurement and Significance." In Proceedings of the Business and Economics Statistics Section. Alexandria, VA: American Statistical Association, 1962, pp. 98-103.

Plosser, Charles I. and Schwert, G. William. "Potential GNP: Its Measurement and Significance: A Dissenting Opinion." Carnegie-Rochester Conference Series on Public Policy, 1979, 10(1), pp. 179-86.

Romer, David. Advanced Macroeconomics. Third Edition. New York: McGraw-Hill/Irwin, 2006.

Sönger, Leopold and Stiassny, Alfred. "An Analysis on the Structural Stability of Okun's Law-A Cross-Country Study." Applied Economics, 2002, 14(34), pp. 1775-87. 


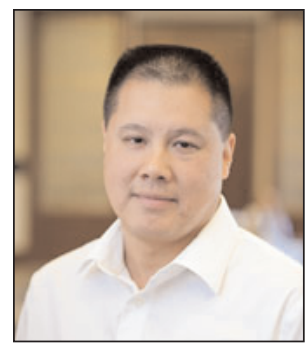

\section{Michael T. Owyang}

Research officer and economist, Federal Reserve Bank of St. Louis

http://research.stlouisfed.org/econ/owyang/

\section{Research Focus}

Michael Owyang's main areas of research are in Bayesian econometrics, time-series econometrics, and forecasting.

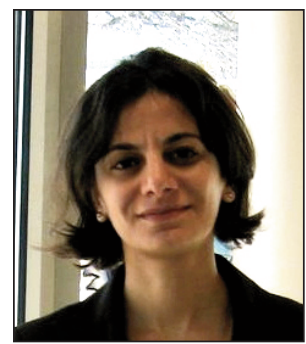

\section{Tatevik Sekhposyan}

Senior analyst, International Economic Analysis Department, Bank of Canada

http://www.bankofcanada.ca/author/tatevik-sekhposyan/

\section{Research Focus}

Tatevik Sekhposyan's research focus areas include applied macroeconomics, time-series and Bayesian econometrics, and forecasting. 